University of Wollongong

Research Online

Australian Institute for Innovative Materials -

Papers

Australian Institute for Innovative Materials

$1-1-2018$

Interfacial contributions to anomalous Hall effect in perpendicular magnetic anisotropic [Co2MnSi/Pd]3 multilayer

Huarui Fu

Xi'an University of Technology

Caiyin You

Xi'an University of Technology

Li Ma

Xi'an University of Technology

Na Tian

Xi'an University of Technology

Fangqing Xin

Xi'an University of Technology

See next page for additional authors

Follow this and additional works at: https://ro.uow.edu.au/aiimpapers

Part of the Engineering Commons, and the Physical Sciences and Mathematics Commons

Research Online is the open access institutional repository for the University of Wollongong. For further information contact the UOW Library: research-pubs@uow.edu.au 


\title{
Interfacial contributions to anomalous Hall effect in perpendicular magnetic anisotropic [Co2MnSi/Pd]3 multilayer
}

\author{
Abstract \\ Through engineering the interface between Co2MnSi and $\mathrm{Pd}$, we realize a high perpendicular magnetic \\ anisotropy (PMA) and controllable anomalous Hall effect (AHE) in [Co2MnSi(tCMS)/Pd]3multilayers. The \\ multilayers are characterized by a particulatelike layer morphology following annealing at $573 \mathrm{~K}$ with \\ weak B2 crystallographic ordering of the Co2MnSi layer. The largest PMA (Keff) of $1.2 \times 106 \mathrm{erg} / \mathrm{cm} 3$ has \\ been obtained in [Co2MnSi(1.2nm)/Pd] 3 multilayer annealed at $573 \mathrm{~K}$. The AHE can be tuned, which we \\ attribute to a varying proximity effect at the Co2MnSi/Pd interface, by varying the annealing temperature \\ and Co2MnSi thickness. According to the expanded AHE scaling relation, we calculate the different \\ contributions to the origin of AHE. Both skew scattering and side jump decrease monotonically with \\ increasing Co2MnSi thickness, but show maximum values for the multilayer annealed around $573 \mathrm{~K}$ with \\ increasing annealing temperature. It is found that skew scattering ( $\rho s s)$ and side-jump scattering ( $\rho s j$ ) \\ exhibit opposite contributions to the AHE; the skew scattering $\rho s s$ is larger than the value of side jump

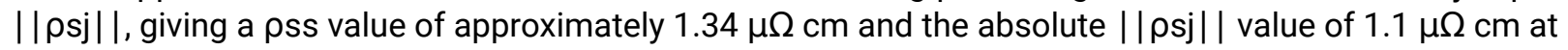 \\ $5 \mathrm{~K}$ in [Co2MnSi(1.2nm)/Pd]3 multilayer, indicating that the overall AHE originates mostly from the skew \\ scattering.

\section{Keywords} \\ hall, [co2mnsi/pd]3, anomalous, multilayer, interfacial, effect, contributions, perpendicular, magnetic, \\ anisotropic \\ Disciplines \\ Engineering | Physical Sciences and Mathematics

\section{Publication Details} \\ Fu, H., You, C., Ma, L., Tian, N., Xin, F., Cheng, Z., Basha, A. \& Kohn, A. (2018). Interfacial contributions to \\ anomalous Hall effect in perpendicular magnetic anisotropic [Co2MnSi/Pd]3 multilayer. Physical Review \\ Materials, 2 (12), 124404-1-124404-8.
}

\section{Authors}

Huarui Fu, Caiyin You, Li Ma, Na Tian, Fangqing Xin, Zhenxiang Cheng, Adham Basha, and Amit Kohn 


\title{
Interfacial contributions to anomalous Hall effect in perpendicular magnetic anisotropic $\left[\mathrm{Co}_{2} \mathrm{MnSi} / \mathrm{Pd}\right]_{3}$ multilayer
}

\author{
Huarui Fu, ${ }^{1}$ Caiyin You,,${ }^{1, *}$ Li Ma, ${ }^{1}$ Na Tian, ${ }^{1}$ Fangqing Xin, ${ }^{1}$ Zhenxiang Cheng, ${ }^{2, *}$ Adham Basha, ${ }^{3}$ and Amit Kohn ${ }^{3}$ \\ ${ }^{1}$ School of Materials Science and Engineering, Xi'an University of Technology, Xi'an 710048, People's Republic of China \\ ${ }^{2}$ Institute for Superconducting \& Electronic Materials, University of Wollongong, New South Wales 2500, Australia \\ ${ }^{3}$ Department of Materials Science and Engineering, Faculty of Engineering, Tel Aviv University, Ramat Aviv, Tel Aviv 6997801, Israel
}

(Received 4 July 2018; published 28 December 2018)

\begin{abstract}
Through engineering the interface between $\mathrm{Co}_{2} \mathrm{MnSi}$ and $\mathrm{Pd}$, we realize a high perpendicular magnetic anisotropy (PMA) and controllable anomalous Hall effect $(\mathrm{AHE})$ in $\left[\mathrm{Co}_{2} \mathrm{MnSi}\left(t_{\mathrm{CMS}}\right) / \mathrm{Pd}\right]_{3}$ multilayers. The multilayers are characterized by a particulatelike layer morphology following annealing at $573 \mathrm{~K}$ with weak B2 crystallographic ordering of the $\mathrm{Co}_{2} \mathrm{MnSi}$ layer. The largest PMA $\left(K_{\text {eff }}\right)$ of $1.2 \times 10^{6} \mathrm{erg} / \mathrm{cm}^{3}$ has been obtained in $\left[\mathrm{Co}_{2} \mathrm{MnSi}(1.2 \mathrm{~nm}) / \mathrm{Pd}\right]_{3}$ multilayer annealed at $573 \mathrm{~K}$. The AHE can be tuned, which we attribute to a varying proximity effect at the $\mathrm{Co}_{2} \mathrm{MnSi} / \mathrm{Pd}$ interface, by varying the annealing temperature and $\mathrm{Co}_{2} \mathrm{MnSi}$ thickness. According to the expanded AHE scaling relation, we calculate the different contributions to the origin of AHE. Both skew scattering and side jump decrease monotonically with increasing $\mathrm{Co}_{2} \mathrm{MnSi}$ thickness, but show maximum values for the multilayer annealed around $573 \mathrm{~K}$ with increasing annealing temperature. It is found that skew scattering $\left(\rho_{\mathrm{ss}}\right)$ and side-jump scattering $\left(\rho_{\mathrm{sj}}\right)$ exhibit opposite contributions to the AHE; the skew scattering $\rho_{\mathrm{ss}}$ is larger than the value of side jump $\left|\rho_{\mathrm{sj}}\right|$, giving a $\rho_{\mathrm{ss}}$ value of approximately $1.34 \mu \Omega \mathrm{cm}$ and the absolute $\left|\rho_{\mathrm{sj}}\right|$ value of $1.1 \mu \Omega \mathrm{cm}$ at $5 \mathrm{~K}$ in $\left[\mathrm{Co}_{2} \mathrm{MnSi}(1.2 \mathrm{~nm}) / \mathrm{Pd}\right]_{3}$ multilayer, indicating that the overall AHE originates mostly from the skew scattering.
\end{abstract}

DOI: 10.1103/PhysRevMaterials.2.124404

\section{INTRODUCTION}

The anomalous Hall effect (AHE) originates from spinorbit interactions, presenting potential applications in magnetic sensors, memories, and logic gates [1-3]. Currently, the AHE of ferromagnetic Heusler alloy films with perpendicular magnetic anisotropy is attracting significant scientific and technological interest due to high spin polarization and reduced Zeeman energy when subjected to a magnetic field [4-6]. The most pressing objectives are to clarify the origin of AHE and therefore to improve the device performance $[6,7]$. A scaling law between longitudinal resistivity $\left(\rho_{x x}\right)$ and anomalous Hall resistivity $\left(\rho_{\mathrm{AH}}\right)$ has been proposed in order to interpret the physical origin of AHE, which is related to both intrinsic and extrinsic contributions [8-10]. In addition, perpendicular magnetic anisotropy (PMA) is another key factor for improving the performance of magnetic sensors and nonvolatile memory devices, particularly reducing energy consumption and enhancing storage density [7,11]. However, to date, studies relating PMA and AHE of high-spin-polarized Heusler alloy films are very limited, although the PMA-based AHE behavior is of fundamental scientific interest with enormous potential applications.

Regarding the physical origin of AHE, the intrinsic contribution follows a $\rho_{\mathrm{AH}} \propto \rho_{x x}^{2}$ relation, relating to the Berry curvature for Bloch electrons in ferromagnetic materials [8]. Scaling relations of $\rho_{\mathrm{AH}} \propto \rho_{x x}$ and $\rho_{\mathrm{AH}} \propto \rho_{x x}^{2}$ are for

\footnotetext{
*Corresponding authors: caiyinyou@xaut.edu.cn; cheng@uow.edu.au
}

extrinsic contributions of skew scattering and side jump, respectively, which can be ascribed to the asymmetric scattering of electrons [9,10]. Tian et al. proposed the scaling relation for epitaxial thin Fe films deposited on GaAs (001) [12] defined as

$$
\rho_{\mathrm{AH}}=\rho_{\mathrm{ss}}+\rho_{\mathrm{sj}}+\rho_{\mathrm{in}}=a^{\prime} \rho_{x x 0}+a^{\prime \prime} \rho_{x x \mathrm{~T}}+b \rho_{x x}^{2},
$$

where $\rho_{\mathrm{ss}}=a^{\prime} \rho_{x x 0}+a^{\prime \prime} \rho_{x x \mathrm{~T}}$ represents a skew scattering contribution. The $\rho_{x x 0}$ term is the residual resistivity arising from scattering of impurities and the $\rho_{x x \mathrm{~T}}\left(\rho_{x x \mathrm{~T}}=\rho_{x x}-\right.$ $\left.-\rho_{x x 0}\right)$ term is the phonon-induced resistivity. The scaling parameters $a^{\prime}$ and $a^{\prime \prime}$ correspond to skew scattering. The $\rho_{\mathrm{sj}}$ term is due to the scattering-independent mechanism of side jump and the $\rho_{\text {in }}$ term is due to the intrinsic mechanism of bulk relating to Berry curvature, both of which are contributed by $b \rho_{x x}^{2}$. The scaling parameter $b$ corresponds to both intrinsic mechanism and side jump. The scaling relation in Eq. (1) allows one to quantify the contribution of skew scattering. The contribution of the side-jump mechanism can be quantified by excluding the contribution from the intrinsic mechanism or directly evaluated in ultrathin films where the bulk intrinsic contribution is negligible [13].

The interface between ferromagnetic (FM) and nonferromagnetic (NM) layers results in various phenomena, such as the magnetic proximity effect, interfacial Rashba effect, and controllable spin-orbit coupling, all of which are critical to electrical transport properties including AHE, spin Hall effect, and other spin-related effects [14-16]. Studies reported that the magnitude of AHE can be strengthened by the addition of nonferromagnetic impurities into bulk ferromagnets [17], enhancing surface/interface scattering through 
granular films [18], multilayer films [19], incorporating the semiconducting layer into magnetic films [20], and achieving PMA [7,11]. Studies of AHE related to PMA have focused on FM/NM bilayer, trilayer, or multilayer with transition-metal FM layers such as $\mathrm{Co}, \mathrm{Fe}$, or $\mathrm{CoFeB}$, and $\mathrm{NM}$ layers such as $\mathrm{Pd}$, Pt, $\mathrm{HfO}_{2}$, or $\mathrm{MgO}$ [21-26]. Recently, Co-based Heusler alloys have attracted intense attention as potential candidates for spintronic devices due to their high Curie temperature and half-metallic electronic structure $[5,27]$. Reported AHE studies on Co-based Heusler alloys include bulk, granular film, bilayer, or trilayer systems, such as bulk $\mathrm{Co}_{2} \mathrm{MnSi}_{1-x} \mathrm{Al}_{x}$ [28], $\mathrm{Co}_{2} \mathrm{FeSi}-\mathrm{Al}_{2} \mathrm{O}_{3}$ granular films, $\mathrm{Co}_{2} \mathrm{MnAl}, \mathrm{Co}_{2} \mathrm{FeSi}, \mathrm{Co}_{2} \mathrm{FeAl}, \mathrm{Co}_{2} \mathrm{MnGe}$, and $\mathrm{Co}_{2} \mathrm{MnSi}$ monolayers [6,29-31], $\mathrm{Pt} / \mathrm{Co}_{2} \mathrm{FeAl}$ bilayer [32], or $\mathrm{MgO} / \mathrm{Co}_{2} \mathrm{MnGa} / \mathrm{Pd}$ trilayer [33]. In our previous report, a large PMA was realized in $\mathrm{Pd} / \mathrm{Co}_{2} \mathrm{MnSi} / \mathrm{MgO}$ trilayer, which was attributed to the interfacial orbital hybridization adjacent to the Heusler alloy $\mathrm{Co}_{2} \mathrm{MnSi}$ layer, namely, $\mathrm{Pd} / \mathrm{Co}_{2} \mathrm{MnSi}$ and $\mathrm{Co}_{2} \mathrm{MnSi} / \mathrm{MgO}$ interfaces [34]. In addition, the enhanced AHE was observed in $\mathrm{Pd} / \mathrm{Co}_{2} \mathrm{MnSi} / \mathrm{MgO}$ multilayer with PMA behavior [35].

Therefore, it can be concluded that the AHE and PMA can be controlled through interfacial engineering, and improved AHE is expected from a perpendicularly magnetized FM layer in Heusler alloy/NM multilayer films [35]. Understanding these interfacial phenomena is a key objective to clarify the source of AHE in Co-based Heusler alloys and consequently its utilization in devices. In this work, we incorporated and examined interfacial contributions into the design of $\left[\mathrm{Co}_{2} \mathrm{MnSi}\left(t_{\mathrm{CMS}}\right) / \mathrm{Pd}\right]_{3}$ multilayer films to show that PMA and AHE can be tuned by annealing temperature and thickness of the $\mathrm{FM} \mathrm{Co} 2 \mathrm{MnSi}$ layer. The role of interface is examined by relating the structure of the multilayers to their transport properties. We applied the expanded scaling relation [12] to elucidate that both skew scattering $\rho_{\mathrm{ss}}$ and side jump $\left|\rho_{\mathrm{sj}}\right|$ contribute to AHE origin in $\left[\mathrm{Co}_{2} \mathrm{MnSi}\left(t_{\mathrm{CMS}}\right) / \mathrm{Pd}\right]_{3}$ multilayers, with the dominant mechanism being skew scattering compared to the side-jump mechanism.

\section{EXPERIMENT}

Multilayer stacks of $\mathrm{Pd}(8 \mathrm{~nm}) /\left[\mathrm{CO}_{2} \mathrm{MnSi}\left(t_{\mathrm{CMS}}\right) /\right.$ $\operatorname{Pd}(1.6 \mathrm{~nm})]_{3} / \mathrm{Pd}(4 \mathrm{~nm})\left(t_{\mathrm{CMS}}=0.7-2.1 \mathrm{~nm}\right)($ referred to as $\left.\left[\mathrm{Co}_{2} \mathrm{MnSi}\left(t_{\mathrm{CMS}}\right) / \mathrm{Pd}\right]_{3}\right)$ were deposited on $\mathrm{Si} / \mathrm{SiO}_{2}(500 \mathrm{~nm})$ substrates by magnetron sputtering (MSP3220, Beijing Jinshengweina Technology Co., Ltd.) under a base pressure of below $3 \times 10^{-5} \mathrm{~Pa}$ at room temperature. The Pd layer was deposited under Ar pressure of $0.3 \mathrm{~Pa}$ with de power of $10 \mathrm{~W}$. The $\mathrm{Co}_{2} \mathrm{MnSi}$ layer was deposited under Ar pressure of $0.3 \mathrm{~Pa}$ with de power of $20 \mathrm{~W}$ using a $\mathrm{Co}_{2} \mathrm{MnSi}$ target (99.5\% purity, Heifei Kejing Materials Technology Co., Ltd.). The thickness of each layer was calibrated by comparison to cross-sectional micrographs obtained by transmission electron microscopy.

The multilayers were then annealed in a vacuum chamber of better than $10^{-5} \mathrm{~Pa}$ for $30 \mathrm{~min}$, at temperatures between 523 and $623 \mathrm{~K}$. The thicknesses and roughness of multilayer films were characterized with $\mathrm{x}$-ray reflectivity (XRR, XRD-7000, Shimadzu Limit, $\mathrm{Cu} K \alpha$ radiation). The crystallographic structure of the ultrathin layers was characterized by Cs-corrected high-resolution (phase contrast) transmission electron microscopy (TEM) (FEI Titan, $300 \mathrm{kV}$ ) in order to reduce delocalization of information [36]. Further qualitative compositional characterizations of the multilayers were achieved by Z-contrast (high-angle annular dark-field) scanning TEM (JEOL JEM 2100F, $200 \mathrm{kV}$ ). Selected samples were prepared for cross-sectional observation, aligning the multilayers edge-on along the Si [110] zone axis. The TEM samples were prepared by mechanical polishing and lowenergy Ar ion milling. The magnetic properties of multilayers were measured by VSM integrated into a physical property measurement system (PPMS, Quantum Design PPMS9). Electrical transport measurements (Hall effect, electrical resistance, and magnetoresistance) were performed on the multilayers with $10 \times 10 \mathrm{~mm}^{2}$ Hall bar profile by PPMS at temperatures between 5 and $300 \mathrm{~K}$.

\section{RESULTS AND DISCUSSION}

\section{A. Structural characterization}

Figure 1(a) shows the x-ray reflectivity (XRR) pattern of $\left[\mathrm{Co}_{2} \mathrm{MnSi}(1.2 \mathrm{~nm}) / \mathrm{Pd}\right]_{3}$ multilayers following different annealing temperatures. The numbers of Kiessig fringes are approximately constant with the increase of annealing temperature, indicating similar roughness in the multilayer. Figures 1(b) and 1(c) show typical cross-sectional Cs-corrected high-resolution (HR)TEM micrographs, here of the $\left[\mathrm{Co}_{2} \mathrm{MnSi}(1.2 \mathrm{~nm}) / \mathrm{Pd}\right]_{3}$ multilayer, annealed at $573 \mathrm{~K}$, which exhibits both high PMA and AHE (shown later). The contrast variations are attributed predominately to $\mathrm{Co}_{2} \mathrm{MnSi}$ and $\mathrm{Pd}$ regions. The power spectra of the Fourier transform from the region denoted schematically by the red rectangle [inset of Fig. 1(b)] shows peaks attributed mostly to crystal periodicities with cubic symmetry of $\{220\}$ and $\{400\}$ planes, and minor peaks attributed to periodicities of $\{200\}$ and $\{420\}$ planes, indicating a $\mathrm{B} 2$ ordered structure of $\mathrm{Co}_{2} \mathrm{MnSi}$. This observation is in agreement with our previous work on the B2 ordered structure of $\mathrm{Co}_{2} \mathrm{MnSi}$ film annealed at $573 \mathrm{~K}$ [34]. Other periodicities in the power spectrum, marked schematically by blue circles, denote $\operatorname{Pd}\{111\}$ and $\{311\}$ planes. The Z-contrast high-angle annular dark-field (HAADF) scanning transmission electron microscopy (STEM) micrograph [Fig. 1(d)] highlights a compositional particulate-layer morphology [36]. The top and bottom $\mathrm{Co}_{2} \mathrm{MnSi}$ layers (relatively dark contrast) are observed to be partially continuous, while the second, intermediate $\mathrm{Co}_{2} \mathrm{MnSi}$ layer cannot be differentiated from the Pd layer.

\section{B. Perpendicular magnetic anisotropy (PMA)}

Figures 2(a)-2(c) show magnetic hysteresis $(M-H)$ loops measured along in-plane and out-of-plane directions at room temperature for $\left[\mathrm{Co}_{2} \mathrm{MnSi}\left(t_{\mathrm{CMS}}\right) / \mathrm{Pd}\right]_{3}$ multilayers following different annealing temperatures and $\mathrm{Co}_{2} \mathrm{MnSi}$ thicknesses. As seen from Fig. 2(a), the as-deposited $\left[\mathrm{Co}_{2} \mathrm{MnSi}(1.2 \mathrm{~nm}) / \mathrm{Pd}\right]_{3}$ multilayer presents an in-plane magnetic anisotropy (IMA). After annealing at $573 \mathrm{~K}$, the easy axis of magnetization was shifted from the in-plane direction to out-of-plane direction, exhibiting a strong PMA behavior, as shown in Fig. 2(b). For the $\left[\mathrm{Co}_{2} \mathrm{MnSi}(2.1 \mathrm{~nm}) / \mathrm{Pd}\right]_{3}$ multilayer annealed at $573 \mathrm{~K}$, a 


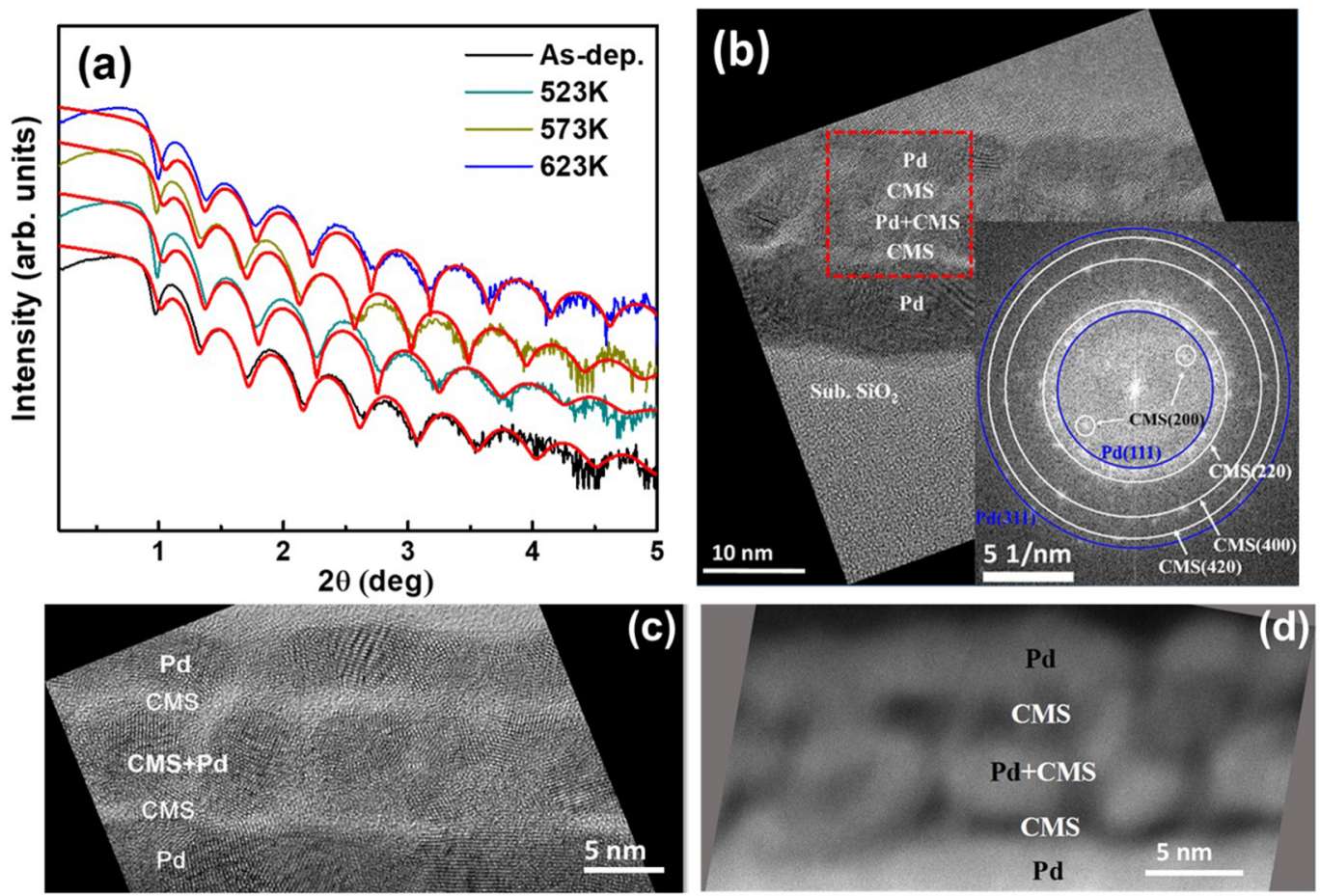

FIG. 1. (a) XRR spectra of $\left[\mathrm{Co}_{2} \mathrm{MnSi}(1.2 \mathrm{~nm}) / \mathrm{Pd}\right]_{3}$ multilayers after several annealing temperatures. (b) Cross-sectional Cs-corrected HRTEM micrograph of $\left[\mathrm{Co}_{2} \mathrm{MnSi}(1.2 \mathrm{~nm}) / \mathrm{Pd}\right]_{3}$ multilayer after annealing at $573 \mathrm{~K}$. Inset: Power spectrum of area marked schematically by red square. (c), (d) Cross-sectional Cs-corrected HRTEM and Z-contrast HAADF STEM micrographs, respectively.

relatively weak PMA behavior was observed, as seen in Fig. 2(c), implying that increasing $\mathrm{Co}_{2} \mathrm{MnSi}$ thickness tends to weaken the PMA.

In order to quantify the PMA, the effective anisotropy energy $\left(K_{\text {eff }}\right)$ is plotted with respect to total $\mathrm{Co}_{2} \mathrm{MnSi}$ thickness $\left(t^{\prime}{ }_{\text {CMS }}\right)$ and annealing temperature $\left(T_{\text {ann }}\right)$ in Fig. 2(d). $K_{\text {eff }}$ is calculated using the empirical relationship $K_{\text {eff }}=H_{k} M_{s} / 2$, in which $H_{\mathrm{k}}$, the anisotropy field, and $M_{\mathrm{s}}$, the saturation magnetic moment, are extracted from the $M-H$ loops, as shown in Table I. Positive $K_{\text {eff }}$ values indicate the PMA behavior of the film. As shown in Fig. 2(d), regarding the as-deposited films, the positive $K_{\text {eff }}$ value for PMA can only be obtained at $t_{\mathrm{CMS}}=0.7 \mathrm{~nm}\left(t^{\prime} \mathrm{CMS}=2.1 \mathrm{~nm}\right)$, and the IMA becomes strong with increasing $t_{\mathrm{CMS}}$, showing large negative $K_{\text {eff values. }}$

Through fitting the phenomenological relation [37],

$$
K_{\mathrm{eff}} \times t_{\mathrm{CMS}}^{\prime}=\left(K_{\mathrm{V}}-2 \pi M_{s}^{2}\right) \times t_{\mathrm{CMS}}^{\prime}+K_{s},
$$
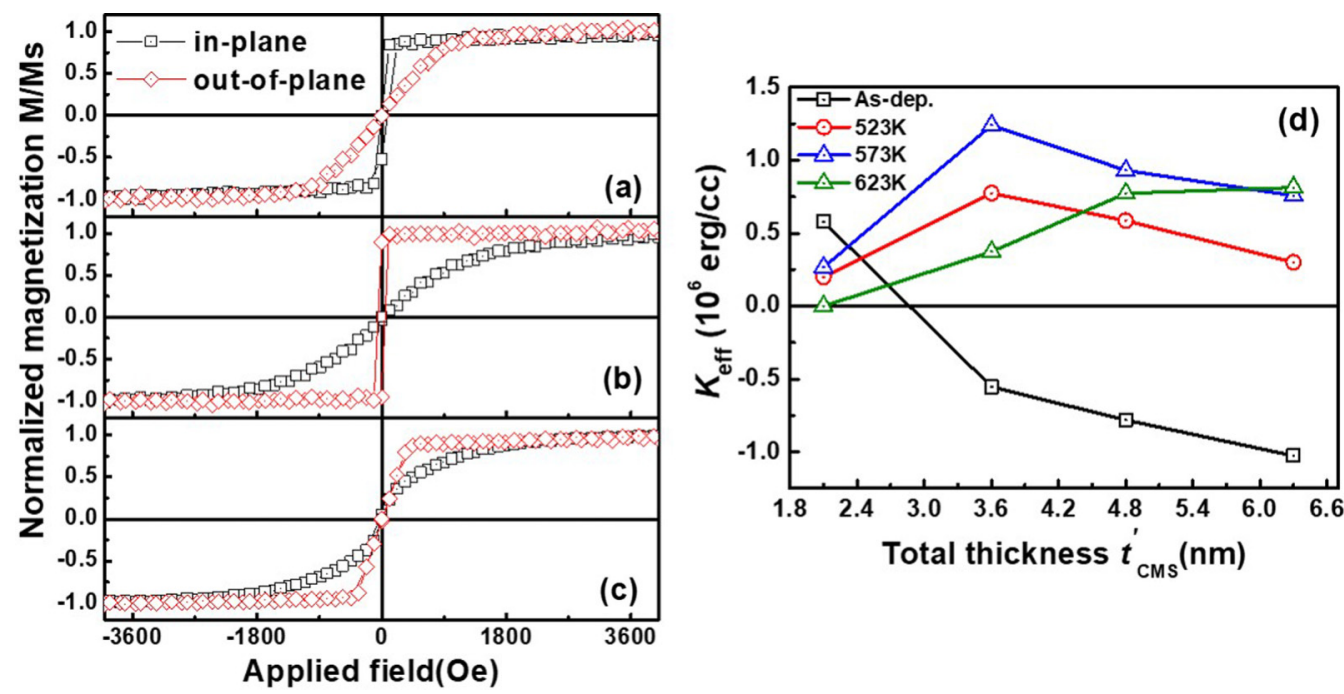

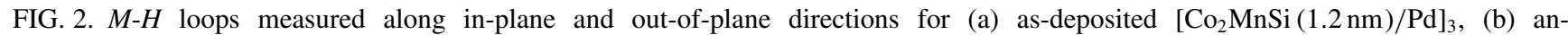
nealed $\left[\mathrm{Co}_{2} \mathrm{MnSi}(1.2 \mathrm{~nm}) / \mathrm{Pd}\right]_{3}$, and (c) $\left[\mathrm{Co}_{2} \mathrm{MnSi}(2.1 \mathrm{~nm}) / \mathrm{Pd}\right]_{3}$ multilayers annealed at $573 \mathrm{~K}$. (d) Dependence of $K_{\text {eff }}$ on $t^{\prime}{ }_{\mathrm{CMS}}$ for $\left[\mathrm{Co}_{2} \mathrm{MnSi}\left(t_{\mathrm{CMS}}\right) / \mathrm{Pd}\right]_{3}$ multilayers following different annealing temperatures. 
TABLE I. Magnetic parameters for different samples.

\begin{tabular}{|c|c|c|c|c|c|}
\hline$t_{\mathrm{CMS}}$ & Parameters & $300 \mathrm{~K}$ & $523 \mathrm{~K}$ & $573 \mathrm{~K}$ & $623 \mathrm{~K}$ \\
\hline \multirow{2}{*}{$0.7 \mathrm{~nm}$} & $M_{\mathrm{s}}\left(\mathrm{emu} / \mathrm{cm}^{3}\right)$ & 508.4 & 470.9 & 450.2 & 400.4 \\
\hline & $H_{\mathrm{k}}(\mathrm{Oe})$ & 2277 & 849 & 1185 & 0 \\
\hline \multirow{2}{*}{$1.2 \mathrm{~nm}$} & $M_{\mathrm{s}}\left(\mathrm{emu} / \mathrm{cm}^{3}\right)$ & 668.3 & 723.5 & 833.9 & 789.6 \\
\hline & $H_{\mathrm{k}}(\mathrm{Oe})$ & -1456 & 2142 & 2974 & 946 \\
\hline \multirow{2}{*}{$1.6 \mathrm{~nm}$} & $M_{\mathrm{s}}\left(\mathrm{emu} / \mathrm{cm}^{3}\right)$ & 670.1 & 697.8 & 742.3 & 770.0 \\
\hline & $H_{\mathrm{k}}(\mathrm{Oe})$ & -2332 & 1682 & 2508 & 2007 \\
\hline \multirow{2}{*}{$2.1 \mathrm{~nm}$} & $M_{\mathrm{s}}\left(\mathrm{emu} / \mathrm{cm}^{3}\right)$ & 670.2 & 680.3 & 686.3 & 723.2 \\
\hline & $H_{\mathrm{k}}(\mathrm{Oe})$ & -3062 & 882 & 2201 & 2249 \\
\hline
\end{tabular}

for the as-deposited $\left[\mathrm{Co}_{2} \mathrm{MnSi}(1.2 \mathrm{~nm}) / \mathrm{Pd}\right]_{3}$ multilayer, the interfacial anisotropy $\left(K_{\mathrm{s}}\right)$ value of $0.18 \mathrm{erg} / \mathrm{cm}^{2}$ and the bulk anisotropy $\left(K_{\mathrm{V}}\right)$ value of $\sim 10^{5} \mathrm{erg} / \mathrm{cm}^{3}$ are evaluated, respectively. As for all annealed films, PMA can be observed for $t_{\mathrm{CMS}}$ in the range of 0.7 to $2.1 \mathrm{~nm}$ for all annealing temperatures. The maximum measured $K_{\text {eff }}$ value is around $1.2 \times 10^{6} \mathrm{erg} / \mathrm{cm}^{3}$ for $\left[\mathrm{Co}_{2} \mathrm{MnSi}(1.2 \mathrm{~nm}) / \mathrm{Pd}\right]_{3}$ multilayer annealed at $573 \mathrm{~K}$. In addition, we note that for the thicker $\mathrm{Co}_{2} \mathrm{MnSi}$ layer, a higher annealing temperature is required to achieve PMA in $\left[\mathrm{Co}_{2} \mathrm{MnSi}\left(t_{\mathrm{CMS}}\right) / \mathrm{Pd}\right]_{3}$ multilayers.

Since the PMA originates from the orbital hybridization $3 d$ of ferromagnetic metallic atoms and $5 d$ of noble metallic atoms at the FM/noble metal interface in its bilayer or multilayer systems, the interfacial quality plays a significant role in developing PMA [38]. For $\left[\mathrm{Co}_{2} \mathrm{MnSi}\left(t_{\mathrm{CMS}}\right) / \mathrm{Pd}\right]_{3}$ multilayers with $t_{\mathrm{CMS}}$ of $1.2 \mathrm{~nm}$, as seen in Fig. 2(d), PMA was measured following annealing due to improved crystallinity of the $\mathrm{Co}_{2} \mathrm{MnSi}$ layer and an increased $\mathrm{Co}_{2} \mathrm{MnSi} / \mathrm{Pd}$ interfacial proximity effect. However, for annealing temperatures above $573 \mathrm{~K}$, this interfacial effect may be deteriorated due to intermixing or diffusion at the $\mathrm{Co}_{2} \mathrm{MnSi} / \mathrm{Pd}$ interface, which suppresses orbital hybridization, thus weakening the PMA $[13,34]$. We conclude that achieving PMA in $\left[\mathrm{Co}_{2} \mathrm{MnSi}\left(t_{\mathrm{CMS}}\right) / \mathrm{Pd}\right]_{3}$ multilayers depends on the combination of annealing temperature and $\mathrm{Co}_{2} \mathrm{MnSi}$ thickness $[13,39,40]$.

Figures 3(a)-3(c) show magnetic hysteresis loops of $\left[\mathrm{Co}_{2} \mathrm{MnSi}(1.2 \mathrm{~nm}) / \mathrm{Pd}\right]_{3}$ multilayers measured along the outof-plane direction (hereinafter referred to as to $M-H_{\perp}$ loops). It is shown that the coercivity increases significantly after annealing. For the sample annealed at $523 \mathrm{~K}$, the coercivity reaches $2.87 \mathrm{kOe}$ at $5 \mathrm{~K}$, decreasing with increased measuring temperature, as seen in Fig. 3(b). The coercivity of the film annealed at $573 \mathrm{~K}$ shows a similar trend [Fig. 3(c)]. However, in this case, we observe a kink in the demagnetized curves for measuring temperatures below $100 \mathrm{~K}$. The hysteresis curve represents a balance of exchange coupling, anisotropy, and dipolar energies, which reflects the domain arrangement [41]. At low temperatures, the magnetization reversal of each layer in the $\left[\mathrm{Co}_{2} \mathrm{MnSi}(1.2 \mathrm{~nm}) / \mathrm{Pd}\right]_{3}$ stack is attributed to domain wall generation and propagation, which is independent of adjacent layers, thus leading to separated switching fields of the individual layers [42].

Figure 3(d) shows the temperature dependences of the normalized out-of-plane saturation magnetization $\left(M_{s \perp}\right)$ for $\left[\mathrm{Co}_{2} \mathrm{MnSi}(1.2 \mathrm{~nm}) / \mathrm{Pd}\right]_{3}$ multilayers annealed at different temperatures. The $M_{s \perp}$ values increase significantly with decreasing measuring temperature for all multilayers. The measured $M_{s \perp}$ vs $T$ data of the annealed samples fit well [dashed line in Fig. 3(d)] to Bloch's law of $M_{s \perp}(T)=M_{0}-k B T^{3 / 2}$, where $k$ is the prefactor relating to the interlayer coupling of the multilayer and $B$ is the bulk spin-wave parameter [43]. However, in the case of the as-deposited multilayer, the temperature dependence of $M_{s \perp}$ is approximately linear, which is attributed to a relatively reduced surface/interface spin density originating from the disordered structure of $\mathrm{Co}_{2} \mathrm{MnSi}[43]$.
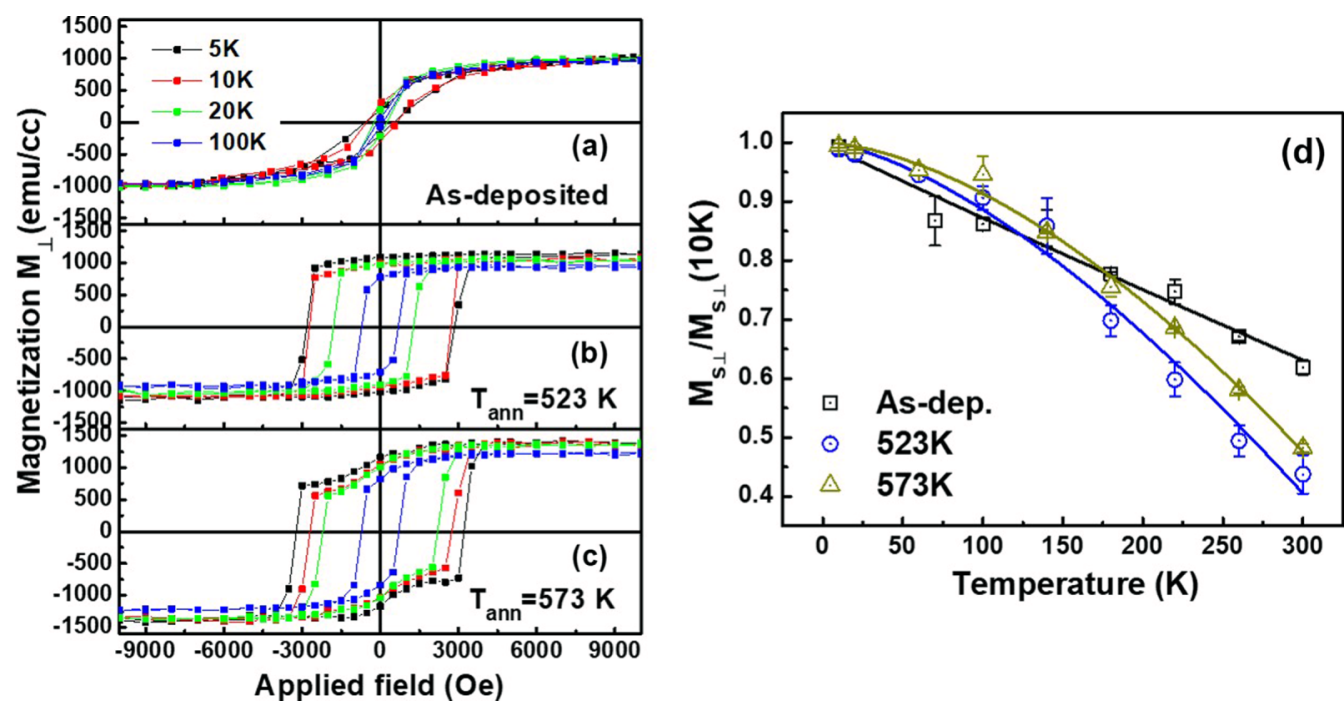

FIG. 3. Out-of-plane magnetic hysteresis loops measured within the low-temperature range from 5 to $100 \mathrm{~K} \mathrm{for}\left[\mathrm{Co}_{2} \mathrm{MnSi}(1.2 \mathrm{~nm}) / \mathrm{Pd}\right]_{3}$ multilayers of the (a) as-deposited and annealed at (b) $523 \mathrm{~K}$ and (c) $573 \mathrm{~K}$. (d) $M_{s \perp}$ vs measuring temperature for $\left[\mathrm{Co}_{2} \mathrm{MnSi}(1.2 \mathrm{~nm}) / \mathrm{Pd}\right]_{3}$ multilayers following different annealing temperatures. The dashed lines represent fitting to Bloch's law. The data are normalized by $M_{s \perp}$ values at $10 \mathrm{~K}$. 


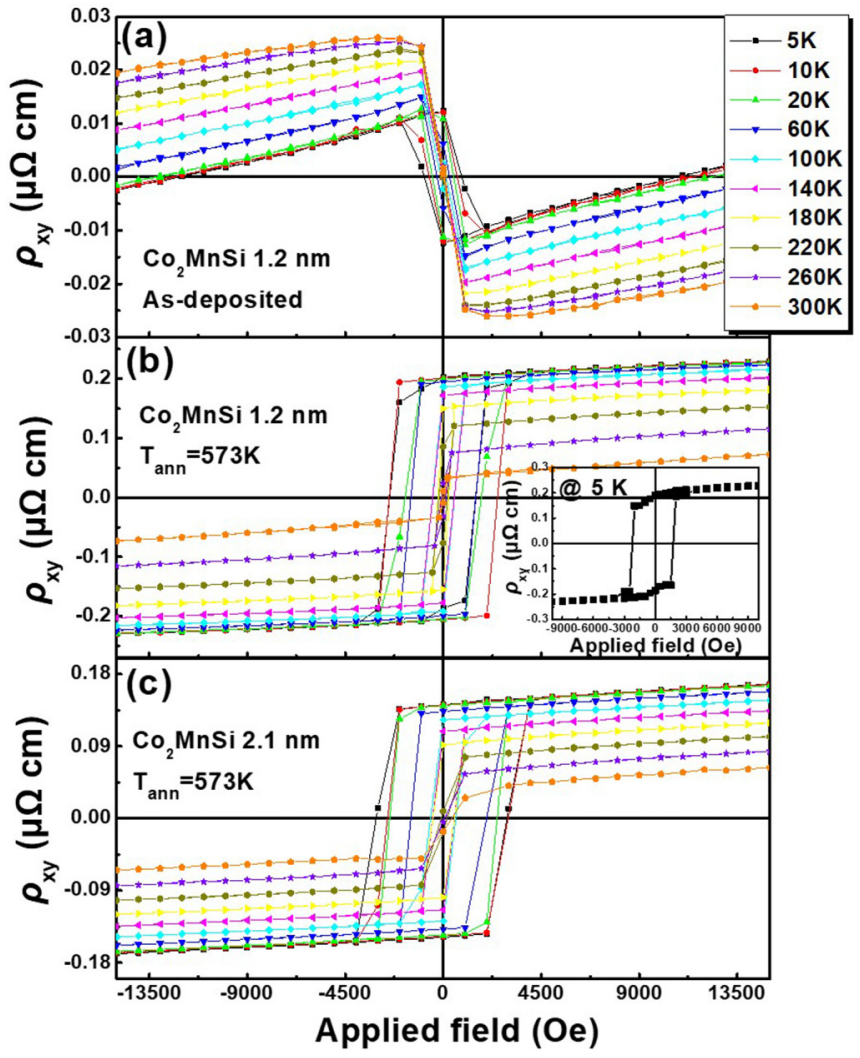

FIG. 4. $\rho_{x y}$ as a function of $H$ for $\left[\mathrm{Co}_{2} \mathrm{MnSi}(1.2 \mathrm{~nm}) / \mathrm{Pd}\right]_{3}$ multilayers of the (a) as-deposited and (b) annealed at $573 \mathrm{~K}$, and $\left[\mathrm{Co}_{2} \mathrm{MnSi}(2.1 \mathrm{~nm}) / \mathrm{Pd}\right]_{3}$ multilayer annealed at (c) $573 \mathrm{~K}$. The inset of (b) gives the Hall loop measured at $5 \mathrm{~K}$, presenting a consistent kink with the $M-H$ loop.

\section{Anomalous Hall effect (AHE)}

In order to elucidate the effect of annealing on AHE, Fig. 4 presents the Hall resistivity $\rho_{x y}$ curves with respect to magnetic field $(H)$ applied perpendicularly to the plane for $\left[\mathrm{Co}_{2} \mathrm{MnSi}\left(t_{\mathrm{CMS}}\right) / \mathrm{Pd}\right]_{3}$ multilayers following different annealing temperatures $\left(T_{\mathrm{ann}}\right)$ and $\mathrm{Co}_{2} \mathrm{MnSi}$ thicknesses $\left(t_{\mathrm{CMS}}\right)$. Generally, the magnetic field dependence of $\rho_{x y}$ can be described by [2]

$$
\rho_{x y}=\rho_{\mathrm{OH}}+\rho_{\mathrm{AH}}=R_{o} H+R_{s} 4 \pi M_{s \perp},
$$

where the $R_{o} H$ term is the normal Hall resistivity coming from the Lorentz force, and the $R_{S} 4 \pi M_{s \perp}$ term is the quantum mechanical phenomenon of the anomalous Hall resistivity. $R_{o}$ and $R_{S}$ are ordinary and anomalous Hall coefficients, respectively, which characterize the strength of these effects. Thus, $\rho_{\mathrm{AH}}$ can be extracted from the Hall curve.

As shown in Fig. 4(a) of the as-deposited $\left[\mathrm{Co}_{2} \mathrm{MnSi}(1.2 \mathrm{~nm}) / \mathrm{Pd}\right]_{3}$ multilayer, $\rho_{x y}$ decreases sharply at low $H$ with a negative slope, following a linear dependence up to its saturation field, and then further increases with increasing $H$. Based on Eq. (3) and the single-band model [44], it is suggested that the charge carriers are electrons and the AHE has a negative value. However, the value of the AHE turns positive after annealing, as seen in Fig. 4(b), which may be the result of different orientations of the easy axis of IMA for the as-deposited film and PMA for the film annealed at $573 \mathrm{~K}$. For the $\left[\mathrm{Co}_{2} \mathrm{MnSi}(2.1 \mathrm{~nm}) / \mathrm{Pd}\right]_{3}$ multilayer with a thicker $\mathrm{Co}_{2} \mathrm{MnSi}$ layer, the field dependence of $\rho_{x y}$ is comparable with that of the $\left[\mathrm{Co}_{2} \mathrm{MnSi}(1.2 \mathrm{~nm}) / \mathrm{Pd}\right]_{3}$ multilayer annealed at $573 \mathrm{~K}$. The difference is that the squareness of the Hall loop decreases slightly (i.e., a relatively weak PMA behavior), in agreement with the magnetic hysteresis loops presented earlier. As shown in Fig. 3(c), a kink was observed for the $M-H$ loops measured at low temperature for the $\left[\mathrm{Co}_{2} \mathrm{MnSi}(1.2 \mathrm{~nm}) / \mathrm{Pd}\right]_{3}$ multilayer annealed at $573 \mathrm{~K}$. When the step size of the applied magnetic field was decreased to the value used for the $M-H$ loops, a consistent kink appears for the Hall loop measured at $5 \mathrm{~K}$ [shown in the inset of Fig. 4(b)].

To further clarify the effect of thermal annealing on the AHE in $\left[\mathrm{Co}_{2} \mathrm{MnSi}\left(t_{\mathrm{CMS}}\right) / \mathrm{Pd}\right]_{3}$ multilayers, Figs. 5(a) and 5 (b) plot the temperature-dependent longitudinal resistivity $\left(\rho_{x x}\right)$ and anomalous Hall resistivity $\left(\rho_{\mathrm{AH}}\right)$ for $\left[\mathrm{Co}_{2} \mathrm{MnSi}(1.2 \mathrm{~nm}) / \mathrm{Pd}\right]_{3}$ multilayers following different annealing temperatures $\left(T_{\mathrm{ann}}\right)$. The value of $\rho_{\mathrm{AH}}$ for each measuring temperature was obtained by extrapolating the Hall loops at large applied magnetic field to zero magnetic field. Figure 5(a) shows that $\rho_{x x}$ increases monotonically with measuring temperature for all multilayers. A positive value of temperature coefficient of longitudinal resistivity $\left(d \rho_{x x} / d T>0\right)$ implies metallic behavior. We note that $\rho_{x x}$ increases slightly with $T$ below $20 \mathrm{~K}$, indicating that the main contribution to $\rho_{x x}$ is residual resistivity due to charge scattering of impurities and atomic disorder within the individual layer and at interfaces [22]. According to Matthiessen's rule [45], a slight reduction of residual resistivity is measured for multilayers with increasing $T_{\text {ann }}$ to 573 and $623 \mathrm{~K}$, respectively.

As shown in Fig. 5(b), $\rho_{\mathrm{AH}}$ displays a weak temperature dependence below $20 \mathrm{~K}$, which is similar to the temperature dependence of $\rho_{x x}$. Above $20 \mathrm{~K}$, the large decrease (as-deposited multilayers) or increase (annealed multilayers) is observed, implying that phonon-induced resistivity is significant in the multilayer. $\rho_{\mathrm{AH}}$ is almost two orders of magnitude smaller than $\rho_{x x}$. For the as-deposited multilayer, $\rho_{\mathrm{AH}}$ increases with the increase of measuring temperature. It is noteworthy that $\rho_{\mathrm{AH}}$ decreases nonlinearly with increasing measuring temperature for all annealed multilayers, which also differs from reports for $\mathrm{Co}_{2} \mathrm{MnSi}$ monolayer and other multilayer systems such as $\mathrm{CoFeB} / \mathrm{Pt}$ and $\mathrm{Fe} / \mathrm{Au}$ [22,24,31], while it is similar to the tendency of Pd/YIG film [46]. For the Pd/YIG system, it is suggested that the magnetic proximity plays an important role in contributing to AHE, which could lead to the decreased $\rho_{\mathrm{AH}}$ with increasing measuring temperature [46]. Thus, the observation of measuring temperature dependence of $\rho_{\mathrm{AH}}$ in our samples implies that interfacial proximity effects exist in the annealed $\left[\mathrm{Co}_{2} \mathrm{MnSi}\left(t_{\mathrm{CMS}}\right) / \mathrm{Pd}\right]_{3}$ multilayers and contribute to the AHE resistivity [46]. Considering the particulatelike-layer structures [Figs. 1(b)-1(d)] in the $\left[\mathrm{Co}_{2} \mathrm{MnSi}(1.2 \mathrm{~nm}) / \mathrm{Pd}\right]_{3}$ multilayers after thermal annealing, this temperature-dependent $\rho_{\mathrm{AH}}$ could be attributed to a strong proximity effect at the $\mathrm{Co}_{2} \mathrm{MnSi} / \mathrm{Pd}$ interfaces resulting in the contribution of magnetic moments from $\mathrm{Pd}$ atoms [46]. Thus, this proximity effect to $\mathrm{Pd}$ adjacent to $\mathrm{Co}_{2} \mathrm{MnSi}$ layer can 

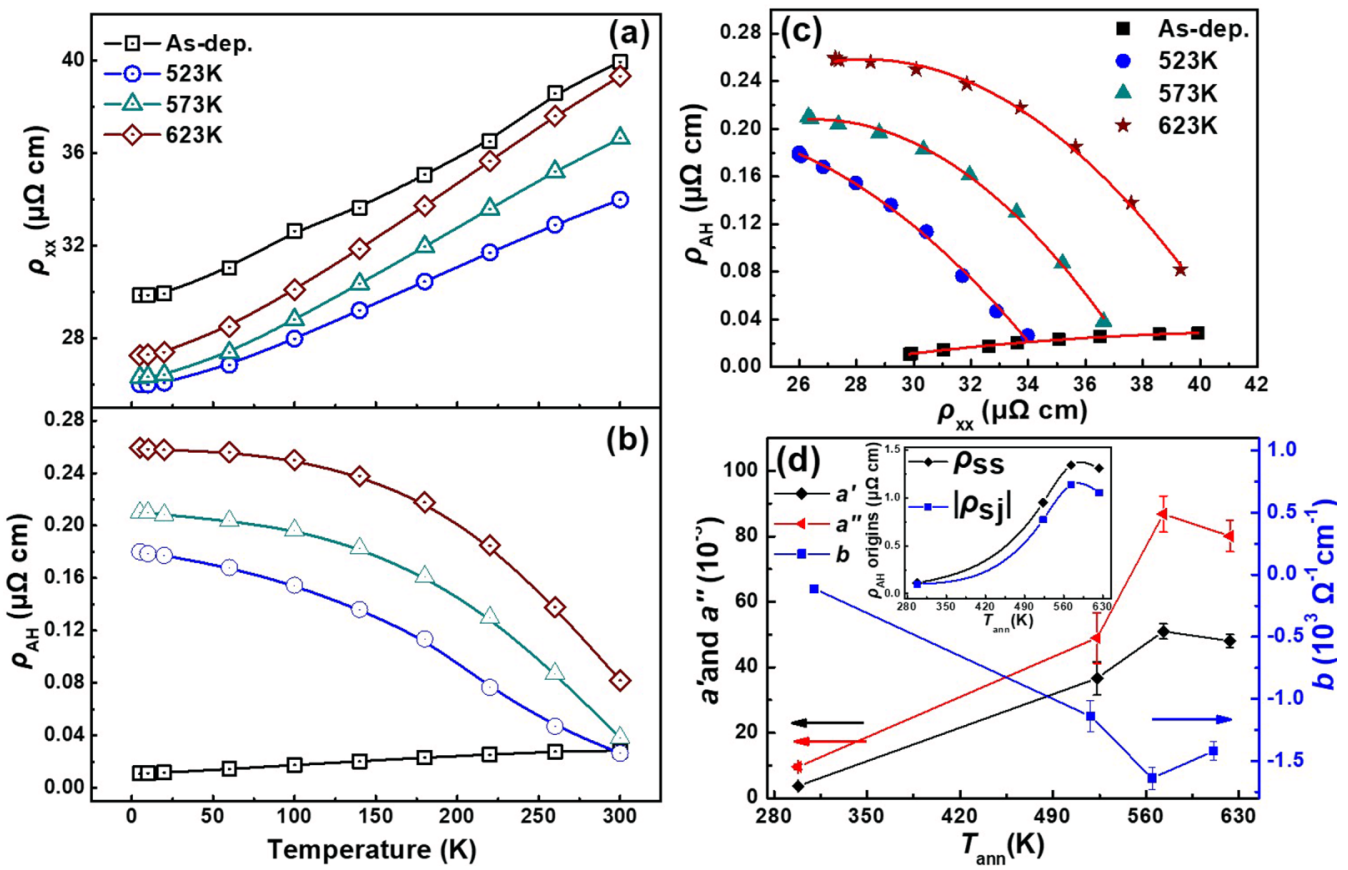

FIG. 5. Temperature dependence of (a) $\rho_{x x}$ and (b) $\rho_{\mathrm{AH}}$ for $\left[\mathrm{Co}_{2} \mathrm{MnSi}(1.2 \mathrm{~nm}) / \mathrm{Pd}\right]_{3}$ multilayers following different annealing temperatures. (c) $\rho_{\mathrm{AH}}$ vs $\rho_{x x}$ fitted with the scaling relation of Eq. (1). (d) $T_{\text {ann }}$ dependence of the scaling parameter $a^{\prime}, a^{\prime \prime}$, and $b$, respectively. Inset: $T_{\text {ann }}$-dependent $\rho_{\mathrm{ss}}$ and $\left|\rho_{\mathrm{sj}}\right|$ at $5 \mathrm{~K}$.

be enhanced and modified by means of thermal annealing. In addition, it is also found that $\rho_{\mathrm{AH}}$ measured at $5 \mathrm{~K}$ increases with the increase of $T_{\mathrm{ann}}$ by a factor of 26 for the multilayer annealed at $623 \mathrm{~K}$ compared to the as-deposited multilayer, although $\rho_{x x}$ remains similar. This remarkable increase can again be attributed to an enhanced proximity effect at the $\mathrm{Co}_{2} \mathrm{MnSi} / \mathrm{Pd}$ interface after annealing [46].

We apply the scaling relation of Eq. (1) reported by Tian et al. [12] in order to determine the charge carrier scattering mechanism of AHE in $\left[\mathrm{Co}_{2} \mathrm{MnSi}(1.2 \mathrm{~nm}) / \mathrm{Pd}\right]_{3}$ multilayers, in particular its dependence on thermal annealing. Figure 5(c) plots $\rho_{\mathrm{AH}}$ as a function of $\rho_{x x}$ for the multilayers following different annealing temperatures. A good fit between $\rho_{x x}$ and $\rho_{\mathrm{AH}}$ is achieved based on Eq. (1). We note that the residual resistivity $\rho_{x x 0}$ is measured at $5 \mathrm{~K}$.

Figure 5(d) presents the variations of the scaling parameters $a^{\prime}, a^{\prime \prime}$, and $b$ following annealing temperature. The inset is the dependence of $\rho_{\mathrm{ss}}$ and $\left|\rho_{\mathrm{sj}}\right|$, measured at $5 \mathrm{~K}$, following various annealing temperatures. The bulk intrinsic contribution is negligible in thin films, namely, the $b \rho^{2}{ }_{x x}$ term dominantly represents the extrinsic contribution of side jump (defined as $\rho_{\mathrm{sj}}=b \rho_{x x}^{2}$ ). The signs of the scaling parameters $a^{\prime}$ and $a^{\prime \prime}$ are the same, opposite to that of $b$, indicating that the skewing scattering mechanism has a positive contribution while the side-jump mechanism has a negative contribution to the overall magnitude of AHE. Notably, the scaling parameter $a^{\prime \prime}$ is not constant with increasing annealing temperature and larger than $a^{\prime}$ for all $\left[\mathrm{Co}_{2} \mathrm{MnSi}(1.2 \mathrm{~nm}) / \mathrm{Pd}\right]_{3}$ multilayers, especially at annealing temperatures above $523 \mathrm{~K}$. This trend indicates that the contribution of phonons to skew scattering is significant $[12,47]$.
In addition, the value of $\rho_{\mathrm{ss}}$ equals $0.11 \mu \Omega \mathrm{cm}$ for the contribution of skew scattering to the AHE mechanism at $5 \mathrm{~K}$ in the as-deposited $\left[\mathrm{Co}_{2} \mathrm{MnSi}(1.2 \mathrm{~nm}) / \mathrm{Pd}\right]_{3}$ multilayer, resulting in a weak AHE with relatively small scaling parameters. The $\left|\rho_{\mathrm{sj}}\right|$ value equals $0.09 \mu \Omega \mathrm{cm}$, which is slightly less than that of the skew scattering causing a low overall AHE in the as-deposited $\left[\mathrm{Co}_{2} \mathrm{MnSi}(1.2 \mathrm{~nm}) / \mathrm{Pd}\right]_{3}$ multilayer. The scaling parameters $a^{\prime}$ and $a^{\prime \prime}$ increase significantly for all annealed multilayers, reaching maximum values of $5.1 \times 10^{-2}$ and $8.7 \times 10^{-2}$ near $573 \mathrm{~K}$, respectively. The absolute value of parameter $b$ displays a similar dependence on $T_{\mathrm{ann}}$, reaching a maximum value of $1.6 \times 10^{3} \Omega^{-1} \mathrm{~cm}^{-1}$ near $573 \mathrm{~K}$. The variation of $\rho_{\mathrm{ss}}$ and $\left|\rho_{\mathrm{sj}}\right|$ with annealing temperature shows a similar trend to the scaling parameters $a^{\prime}$ and $a^{\prime \prime}$. The largest values of $\rho_{\mathrm{ss}}$ and $\left|\rho_{\mathrm{sj}}\right|$ for $\left[\mathrm{Co}_{2} \mathrm{MnSi}(1.2 \mathrm{~nm}) / \mathrm{Pd}\right]_{3}$ multilayers annealed at $573 \mathrm{~K}$ are about 1.34 and $1.1 \mu \Omega \mathrm{cm}$, respectively. Moreover, $\rho_{\mathrm{ss}}$ values in all multilayers are larger than $\left|\rho_{\mathrm{sj}}\right|$, as seen in the inset of Fig. 5(d), implying that skew scattering is strong in $\left[\mathrm{Co}_{2} \mathrm{MnSi}(1.2 \mathrm{~nm}) / \mathrm{Pd}\right]_{3}$ multilayers as compared to the side-jump effect. Here again we observe for $\left[\mathrm{Co}_{2} \mathrm{MnSi}(1.2 \mathrm{~nm}) / \mathrm{Pd}\right]_{3}$ multilayers that thermal annealing influences the $\mathrm{Co}_{2} \mathrm{MnSi} / \mathrm{Pd}$ interface, thus enabling one to tune AHE behavior. The increased skew scattering and side-jump contribution after annealing may account for the enhanced interfacelike scattering between the $\mathrm{Co}_{2} \mathrm{MnSi}$ and Pd regions [26].

In order to examine the influence of the thickness of $\mathrm{Co}_{2} \mathrm{MnSi}$ layers on AHE in $\left[\mathrm{Co}_{2} \mathrm{MnSi}\left(t_{\mathrm{CMS}}\right) / \mathrm{Pd}\right]_{3}$ multilayers, Figs. 6(a) and 6(b) show the temperature dependence of $\rho_{x x}$ and $\rho_{\mathrm{AH}}$ for multilayers annealed at $573 \mathrm{~K}$ with different $\mathrm{Co}_{2} \mathrm{MnSi}$ thicknesses. The temperature-dependent $\rho_{x x}$ for all 

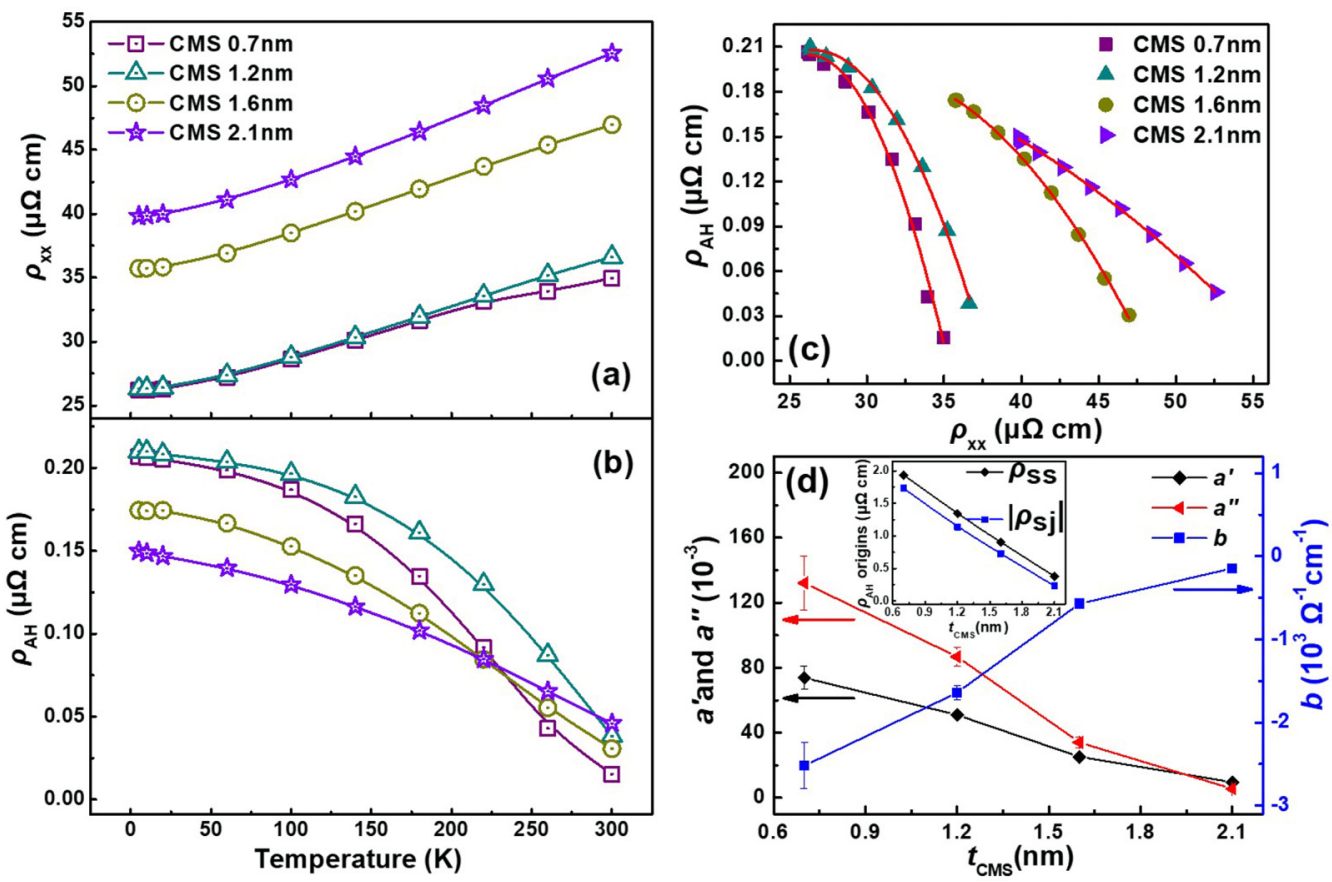

FIG. 6. Dependence of (a) $\rho_{x x}$ and (b) $\rho_{\mathrm{AH}}$ on measurement temperature for $\left[\mathrm{Co}_{2} \mathrm{MnSi}\left(t_{\mathrm{CMS}}\right) / \mathrm{Pd}\right]_{3}$ multilayers annealed at $573 \mathrm{~K}$ for different $t_{\mathrm{CMS}}$. (c) $\rho_{\mathrm{AH}}$ vs $\rho_{x x}$ fitting curves according to Eq. (1). (d) $t_{\mathrm{CMS}}$ dependence of the scaling parameters $b, a^{\prime}$, and $a^{\prime \prime}$, respectively. Inset: The dependence of $\rho_{\mathrm{ss}}$ and $\left|\rho_{\mathrm{sj}}\right|$, measured at $5 \mathrm{~K}$, on $t_{\mathrm{CMS}}$.

multilayers exhibits a metallic nature. $\rho_{x x}$ increases with increasing $\mathrm{Co}_{2} \mathrm{MnSi}$ thickness, particularly at $t_{\mathrm{CMS}}$ beyond 1.2 nm. $\rho_{x x}$ increases by a factor of 1.5 when $t_{\mathrm{CMS}}$ increases from 0.7 to $2.1 \mathrm{~nm}$ at $5 \mathrm{~K}$ owing to the increased contributions from $\mathrm{Co}_{2} \mathrm{MnSi}$ layers. However, $\rho_{\mathrm{AH}}$ decreases by a factor close to 1.5 with increasing $t_{\mathrm{CMS}}$ to $2.1 \mathrm{~nm}$. This observation is consistent with the interpretation of the weakened PMA in the multilayers in a relatively thick $\mathrm{Co}_{2} \mathrm{MnSi}$ layer, attributed to a reduced interface proximity effect.

Figure 6(c) shows good fitting of the relation of $\rho_{x x^{-}}$ dependent $\rho_{\mathrm{AH}}$ with the scaling approximation of Eq. (1) for $\left[\mathrm{Co}_{2} \mathrm{MnSi}\left(t_{\mathrm{CMS}}\right) / \mathrm{Pd}\right]_{3}$ multilayers for different $\mathrm{Co}_{2} \mathrm{MnSi}$ thicknesses $\left(t_{\mathrm{CMS}}\right)$. The scaling parameters of $a^{\prime}, a^{\prime \prime}$, and $b$ as a function of $t_{\mathrm{CMS}}$ are plotted in Fig. 6(d). The inset is the dependence of $\rho_{\mathrm{ss}}$ and $\left|\rho_{\mathrm{sj}}\right|$, measured at $5 \mathrm{~K}$, on $t_{\mathrm{CMS}}$. The scaling parameters of $a^{\prime}$ and $a^{\prime \prime}$ decrease nearly linearly with the increase of $t_{\mathrm{CMS}}$, and the absolute value of parameter $b$ also shows a trend to decrease with increasing $t_{\text {CMS }}$. This trend implies that skew scattering and side-jump contributions to AHE are reduced with increasing $t_{\mathrm{CMS}}$. As shown in the inset of Fig. $6(\mathrm{~d}), \rho_{\mathrm{ss}}$ values in all multilayers are larger than $\left|\rho_{\mathrm{sj}}\right|$ values, indicating that the skew scattering contributes to the overall AHE in contrast to the side-jump mechanism [47].

Thus, by varying the thickness and annealing temperature of the $\mathrm{Co}_{2} \mathrm{MnSi}$ layers, the interfacial interaction can be finely tuned, leading to the enhanced $\mathrm{AHE}$ in $\left[\mathrm{Co}_{2} \mathrm{MnSi}\left(t_{\mathrm{CMS}}\right) / \mathrm{Pd}\right]_{3}$ multilayers. The dependence of AHE on the measurement temperature can be ascribed to the proximity effect at the $\mathrm{Co}_{2} \mathrm{MnSi} / \mathrm{Pd}$ interface, which again can be tuned by varying the annealing temperature and $\mathrm{Co}_{2} \mathrm{MnSi}$ thickness [46].

\section{CONCLUSIONS}

We reported a systematic study on the role of $\mathrm{Co}_{2} \mathrm{MnSi}$ thickness and annealing temperature in $\left[\mathrm{Co}_{2} \mathrm{MnSi}\left(t_{\mathrm{CMS}}\right) / \mathrm{Pd}\right]_{3}$ multilayers on PMA and AHE. By varying the annealing temperature and $\mathrm{Co}_{2} \mathrm{MnSi}$ thickness, a large PMA was achieved for the case of the $\left[\mathrm{Co}_{2} \mathrm{MnSi}(1.2 \mathrm{~nm}) / \mathrm{Pd}\right]_{3}$ multilayer annealed at $573 \mathrm{~K}$ with a $K_{\text {eff }}$ value of $1.2 \times 10^{6} \mathrm{erg} / \mathrm{cm}^{3}$. The relationship between the longitudinal resistivity $\left(\rho_{x x}\right)$ and anomalous Hall resistivity $\left(\rho_{\mathrm{AH}}\right)$ are well fitted by the expanded AHE scaling relation. We show quantitatively the opposite contributions of skew scattering and side-jump mechanisms to AHE in $\left[\mathrm{Co}_{2} \mathrm{MnSi}\left(t_{\mathrm{CMS}}\right) / \mathrm{Pd}\right]_{3}$ multilayers and carefully tune the $\mathrm{Co}_{2} \mathrm{MnSi}$ thickness and annealing temperature to achieve a controllable AHE behavior by balancing the skew scattering and side-jump origins, which is useful for the development and application of AHE-based devices.

\section{ACKNOWLEDGMENTS}

This work was in part supported by the National Natural Science Foundation of China (Grants No. 51771145 and No. 51371140), Shaanxi key R \& D plan, international scientific and technological cooperation and exchange program (Grant No. 2017KW-020), Natural Science Basic Research Plan of Shaanxi Province (Grants No. 2017JM5060 and No. 2018JQ1066), and the ISF-NSFC joint research program (Grant No. 2223/15). 
[1] G. A. Prinz, Science 282, 1660 (1998).

[2] N. Nagaosa, J. Sinova, S. Onoda, A. H. MacDonald, and N. P. Ong, Rev. Mod. Phys. 82, 1539 (2010).

[3] M. M. Hassoun, W. C. Black, E. K. F. Lee, R. L. Geiger, and A. Hurst, IEEE Trans. Magn. 33, 3307 (1997).

[4] R. Shan, H. Sukegawa, W. H. Wang, M. Kodzuka, T. Furubayashi, T. Ohkubo, S. Mitani, K. Inomata, and K. Hono, Phys. Rev. Lett. 102, 246601 (2009).

[5] H.-x. Liu, Y. Honda, T. Taira, K.-i. Matsuda, M. Arita, T. Uemura, and M. Yamamoto, Appl. Phys. Lett. 101, 132418 (2012).

[6] Z. Qin, X.-D. Liu, and Z.-Q. Li, J. Appl. Phys. 111, 083919 (2012).

[7] Y. Zhu and J. W. Cai, Appl. Phys. Lett. 90, 012104 (2007).

[8] R. Karplus and J. M. Luttinger, Phys. Rev. 95, 1154 (1954).

[9] J. Smit, Physica 21, 877 (1955).

[10] L. Berger, Phys. Rev. B 2, 4559 (1970).

[11] H. Yoda, T. Kishi, T. Nagase, M. Yoshikawa, K. Nishiyama, E. Kitagawa, T. Daibou, M. Amano, N. Shimomura, S. Takahashi, T. Kai, M. Nakayama, H. Aikawa, S. Ikegawa, M. Nagamine, J. Ozeki, S. Mizukami, M. Oogane, Y. Ando, S. Yuasa, K. Yakushiji, H. Kubota, Y. Suzuki, Y. Nakatani, T. Miyazaki, and K. Ando, Curr. Appl. Phys. 10, e87 (2010).

[12] Y. Tian, L. Ye, and X. Jin, Phys. Rev. Lett. 103, 087206 (2009).

[13] X. Q. Li, S. Q. Yin, Y. P. Liu, D. L. Zhang, X. G. Xu, J. Miao, and Y. Jiang, Appl. Phys. Express 4, 043006 (2011).

[14] M. Suzuki, H. Muraoka, Y. Inaba, H. Miyagawa, N. Kawamura, T. Shimatsu, H. Maruyama, N. Ishimatsu, Y. Isohama, and Y. Sonobe, Phys. Rev. B 72, 054430 (2005).

[15] L. Liu, O. J. Lee, T. J. Gudmundsen, D. C. Ralph, and R. A. Buhrman, Phys. Rev. Lett. 109, 096602 (2012).

[16] Y. Sun, Y. Ba, A. Chen, W. He, W. Wang, X. Zheng, L. Zou, Y. Zhang, Q. Yang, L. Yan, C. Feng, Q. Zhang, J. Cai, W. Wu, M. Liu, L. Gu, Z. Cheng, C. W. Nan, Z. Qiu, Y. Wu, J. Li, and Y. Zhao, ACS Appl. Mater. Interfaces 9, 10855 (2017).

[17] A. B. Pakhomov, X. Yan, and B. Zhao, Appl. Phys. Lett. 67, 3497 (1995).

[18] A. Gerber, A. Milner, L. Goldshmit, M. Karpovski, B. Lemke, H. U. Habermeier, and A. Sulpice, Phys. Rev. B 65, 054426 (2002).

[19] D. Rosenblatt, M. Karpovski, and A. Gerber, Appl. Phys. Lett. 96, 022512 (2010).

[20] X. Q. Zhang, W. Wang, K. J. Wang, W. Niu, B. L. Li, N. Maltby, M. Yang, M. Gao, W. Q. Liu, L. He, R. Zhang, and Y. B. Xu, J. Phys. D: Appl. Phys. 50, 155002 (2017).

[21] S. L. Zhang, J. Teng, J. Y. Zhang, Y. Liu, J.W. Li, G. H. Yu, and S. G. Wang, Appl. Phys. Lett. 97, 222504 (2010).

[22] Q. Zhang, P. Li, Y. Wen, C. Zhao, J. W. Zhang, A. Manchon, W. B. Mi, Y. Peng, and X. X. Zhang, Phys. Rev. B 94, 024428 (2016).
[23] Z. B. Guo, W. B. Mi, R. O. Aboljadayel, B. Zhang, Q. Zhang, P. G. Barba, A. Manchon, and X. X. Zhang, Phys. Rev. B 86, 104433 (2012).

[24] S. B. Wu, X. F. Yang, S. Chen, and T. Zhu, J. Appl. Phys. 113, 17C119 (2013).

[25] S. L. Jiang, G. Yang, J. Teng, Q. X. Guo, Y. W. Liu, X.-J. Li, and G. H. Yu, J. Magn. Magn. Mater. 433, 42 (2017).

[26] B. Peng, M. M. Feng, Q. Yang, S. S. Zhao, Y. J. Zhang, Z. Y. Zhou, and M. Liu, IEEE Magn. Lett. 8, 2507205 (2017).

[27] T. Kubota, S. Tsunegi, M. Oogane, S. Mizukami, T. Miyazaki, H. Naganuma, and Y. Ando, Appl. Phys. Lett. 94, 122504 (2009).

[28] J. C. Prestigiacomo, D. P. Young, P. W. Adams, and S. Stadler, J. Appl. Phys. 115, 043712 (2014).

[29] K. K. Meng, J. Miao, X. G. Xu, J. H. Zhao, and Y. Jiang, Phys. Lett. A 381, 1202 (2017).

[30] K. K. Meng, J. Miao, X. G. Xu, Y. Wu, J. H. Zhao, and Y. Jiang, Solid State Commun. 254, 48 (2017).

[31] M. Obaida, K. Westerholt, and H. Zabel, Phys. Rev. B 84, 184416 (2011).

[32] Y. Q. Zhang, N. Y. Sun, W. R. Che, X. L. Li, J. W. Zhang, R. Shan, Z. G. Zhu, and G. Su, Appl. Phys. Lett. 107, 082404 (2015).

[33] B. M. Ludbrook, B. J. Ruck, and S. Granville, Appl. Phys. Lett. 110, 062408 (2017).

[34] H. R. Fu, C. Y. You, Y. L. Li, K. Wang, and N. Tian, J. Phys. D: Appl. Phys. 49, 195001 (2016).

[35] H. R. Fu, L. Ma, N. Tian, C. Y. You, and K. Wang, AIP Adv. 8, 055804 (2018).

[36] L. Hannes and L. Michael, Rep. Prog. Phys. 71, 016102 (2008).

[37] C. A. F. Vaz, J. A. C. Bland, and G. Lauhoff, Rep. Prog. Phys. 71, 056501 (2008)

[38] N. Nakajima, T. Koide, T. Shidara, H. Miyauchi, H. Fukutani, A. Fujimori, K. Iio, T. Katayama, M. Nývlt, and Y. Suzuki, Phys. Rev. Lett. 81, 5229 (1998).

[39] H. X. Yang, M. Chshiev, B. Dieny, J. H. Lee, A. Manchon, and K. H. Shin, Phys. Rev. B 84, 054401 (2011).

[40] C. Y. You, H. R. Fu, X. Zhang, N. Tian, and P. W. Wang, J. Magn. Magn. Mater. 377, 276 (2015).

[41] C. Kittel, Rev. Mod. Phys. 21, 541 (1949).

[42] O. Hellwig, T. L. Kirk, J. B. Kortright, A. Berger, and E. E. Fullerton, Nat. Mater. 2, 112 (2003).

[43] B. D. Cullity and C. D. Graham, Introduction to Magnetic Materials (Wiley, New York, 2008).

[44] S. L. Altmann, An Introduction from the Point of View of Symmetry (Clarendon, Oxford University Press, Oxford, 1994).

[45] J. S. Dugdale and Z. S. Basinski, Phys. Rev. 157, 552 (1967).

[46] X. Zhou, L. Ma, Z. Shi, G. Y. Guo, J. Hu, R. Q. Wu, and S. M. Zhou, Appl. Phys. Lett. 105, 012408 (2014).

[47] Y. Wu, Q. M. Zhang, K. K. Meng, J. K. Chen, X. G. Xu, J. Miao, and Y. Jiang, Appl. Phys. Express 10, 063003 (2017). 